\title{
Advanced oxidation protein products and malondialdehyde - the new biological markers of oxidative stress - are elevated in postmenopausal women
}

\author{
Tansel Cakir ${ }^{1}$, Bulent Goktas ${ }^{2}$, Mehmet F. Mutlu³, Ilknur Mutlu4 ${ }^{4}$ Ayse Bilgihan², \\ Mehmet Erdem ${ }^{1}$, Ahmet Erdem ${ }^{1}$ \\ ${ }^{1}$ Department of Obstetrics \& Gynecology, Gazi University Faculty of Medicine, Ankara, Turkey \\ ${ }^{2}$ Department of Biochemistry Gazi University Faculty of Medicine, Ankara, Turkey \\ ${ }^{3}$ Department of Obstetrics \& Gynecology, Koru Hospitals, Ankara, Turkey \\ ${ }^{4}$ IVF Unit, Novaart IVF and Women Health Center, Ankara, Turkey
}

\begin{abstract}
Objectives: The aim of the study was to measure advanced oxidation protein products (AOPPs) as markers for oxidative stress to evaluate cardiovascular risk in pre- and postmenopausal women and to compare the results with malondialdehyde (MDA) levels.

Material and methods: Twenty premenopausal women and 84 naturally postmenopausal patients were enrolled in the study. AOPP and MDA plasma levels were measured. The postmenopausal group was further subdivided into two groups: postmenopausal age of 40-49 and of 50-59 years. AOPP and MDA levels were compared between premenopausal, 40-49 and 50-59 year old menopausal women.

Results: Plasma AOPP and MDA levels in postmenopausal women were increased when compared with their premenopausal peers $(123.83 \pm 55.51 \mu \mathrm{mol} / \mathrm{L}$ vs. $61.59 \pm 16.42 \mu \mathrm{mol} / \mathrm{L}$ and $6.50 \pm 1.05 \mu \mathrm{mol} / \mathrm{L} v s .5 .98 \pm 0.77 \mu \mathrm{mol} / \mathrm{L}$; respectively). Mean plasma AOPP levels in the two menopausal age groups were both significantly higher from the premenopausal group $(118.64 \pm 59.1 \mu \mathrm{mol} / \mathrm{L}$ vs. $61.59 \pm 16.42 \mu \mathrm{mol} / \mathrm{L}$ and $132.31 \pm 48.97 \mu \mathrm{mol} / \mathrm{L}$ vs. $61.59 \pm 16.42 \mu \mathrm{mol} / \mathrm{L}$; respectively). No significant difference was found in mean AOPP levels between postmenopausal subjects of 40-49 and 50-59 years age $(118.64 \pm 59.12 \mu \mathrm{mol} / \mathrm{L}$ vs. $132.31 \pm 48.97 \mu \mathrm{mol} / \mathrm{L})$. Mean plasma MDA levels of each of two postmenopausal age groups were both significantly higher from the premenopausal group $(6.50 \pm 1.04 \mu \mathrm{mol} / \mathrm{L} v \mathrm{~s} .5 .98 \pm 0.77 \mu \mathrm{mol} / \mathrm{L}$ and $6.50 \pm 1.10 \mu \mathrm{mol} / \mathrm{L}$ vs. $5.98 \pm 0.77 \mu \mathrm{mol} / \mathrm{L}$; respectively). However, no statistically significant difference between the two postmenopausal age groups $(6.50 \pm 1.04 \mu \mathrm{mol} / \mathrm{L}$ vs. $6.50 \pm 1.10 \mu \mathrm{mol} / \mathrm{L})$ was found.

Conclusions: AOPP and MDA levels are elevated in postmenopausal women as compared to their premenopausal peers, suggesting they can be used as markers for cardiovascular risk in postmenopausal women.
\end{abstract}

Key words: malondialdehyde, menopause, advanced oxidation protein products

Ginekologia Polska 2016; 87, 5: 321-325

\section{INTRODUCTION}

Oxidative stress is defined as an imbalance between biochemical processes leading to the production of reactive oxygen species (ROS) and those responsible for the removal of ROS, the so-called 'cellular antioxidant cascade' [1]. Oxidative stress is associated with damage to all biomolecules (polynucleotides, proteins, lipids, and sugars) that can lead to a critical failure of biological functions and, ultimately, cell death [2-4]. There is a growing evidence supporting the role of oxidative stress in the pathogenesis of certain chronic diseases (i.e. atherosclerosis, diabetes mellitus, chronic renal failure), certain cancers, and the process of aging $[2,5-9]$. 
Oxidative stress appears to play a key role in the development of cardiovascular diseases related to atherosclerosis. Lipid peroxidation has long been shown to be associated with increased cardiovascular risk. The oxidative modification hypothesis of atherosclerosis suggests that low-density lipoprotein (LDL) oxidation is an important initiating event in atherogenesis $[2,5,8]$. Various products of free radical damage to biomolecules as well as antioxidant defense system mechanisms have been used as biomarkers of oxidative stress status in patients suffering from cardiovascular complications and other chronic diseases believed to be related to oxidative stress $[10,11]$. Advanced oxidation protein products (AOPPs) have been first described in the plasma of uremic patients at high levels as a marker of oxidant-mediated protein damage [12]. AOPPs are predominantly albumin and its aggregates, which are generated following exposure to reactive oxidants from activated phagocytes and have some pro-inflammatory properties $[13,14]$. AOPPs are proposed as one of the possible markers of oxidative injury, which originate under oxidative and carbonyl stress and increase global inflammatory activity. Recently, elevated AOPP levels have also been reported to be associated with increased cardiovascular risk [15-17].

\section{OBJECTIVES}

Although increased blood levels of lipid peroxidation products (malondialdehyde levels) have been reported in postmenopausal women [18-20], there is only one study reporting AOPP levels in postmenopausal women [21].The aim of the study was to measure AOPP and MDA levels in pre and postmenopausal women.

\section{MATERIAL AND METHODS}

A total of 104 subjects were enrolled in the study, including 40 premenopausal women (aged 40-49) with regular menses and 84 postmenopausal women (aged 40-59) with no menses for at least 1 year. Fifty-one of the menopausal women were between 40-49 and 33 were between 50-59 years of age. All patients were healthy and had no history of vascular diseases related to atherosclerosis (i.e. coronary artery disease and hypertension) or any systemic diseases (i.e. chronic renal disease). Smokers, regular consumers of alcohol, antioxidant supplement users were also excluded from the study. None of the patients had taken any hormone replacement therapy or hormonal medication containing estrogen before the study. Local Ethics Committee approved of the study. All subjects provided their informed consent.

Venous blood samples were drawn from patients in fasting state to heparin-coated, EDTA-containing tubes. Following centrifugation, the plasma was stored in Eppendorf tubes at $-80^{\circ} \mathrm{C}$ until analysis. AOPP levels were determined in the plasma using a spectrophotometric method described by Witko-Sarsat et al. [12]. Next, $200 \mu \mathrm{L}$ of plasma were diluted 1:5 with $0.1 \mathrm{~mol} / \mathrm{L}$, pH 7.4, phosphate-buffered saline solution (PBS) and $20 \mathrm{~mL}$ of acetic acid ( $14 \mathrm{~mol} / \mathrm{L})$ and $10 \mathrm{~mL}$ of $1.16 \mathrm{~mol} / \mathrm{L}$ potassium iodide were added. Control wells contained PBS. Chloramine-T solution (0-100 $\mu \mathrm{mol} / \mathrm{L}$ ) was used for calibration. Absorbance was measured at $340 \mathrm{~nm}$ (Schimadzu UV1601) and AOPP concentration was expressed in chloramines-T units ( $\mu \mathrm{mol} / \mathrm{L}$ ). MDA levels were determined in the plasma by means of the thiobarbituric acid (TBA) reaction, as described by Hammouda et al. [22]. A mixture of $0.5 \mathrm{~mL}$ of plasma, $2.5 \mathrm{~mL}$ of trichloroacetic acid $(200 \mathrm{~g} / \mathrm{L})$, and $1 \mathrm{~mL}$ of TBA $(6.7 \mathrm{~g} / \mathrm{L})$ was heated in a boiling water bath for 30 minutes then rapidly cooled. The red complex formed was extracted in $4 \mathrm{~mL}$ of $\mathrm{n}$-butanol. Absorbance was measured at $532 \mathrm{~nm}$ (Schimadzu UV1601), and 1,1,3,3 tetraethoxypropane (Sigma-Aldrich) solution (0-20 $\mu \mathrm{mol} / \mathrm{L})$ was used for calibration. MDA concentration was expressed as $\mu \mathrm{mol} / \mathrm{L}$.

The Statistical Program for Social Sciences (SPSS, version 11.5; SPSS Inc., Chicago, IL) was used for statistical analysis. Plasma AOPP and MDA levels were expressed as mean \pm standard deviation $(x \pm S D)$, and comparisons of these data were analyzed using student $t$-test or one-way ANOVA tests. Nonparametric 'Two-sample Kolmogorov-Smirnov' and Kruskal-Wallis tests were used when assumptions for the $t$-test and one-way Anova tests were not met. Relationships between parameters were determined by Pearson's correlation coefficient. $P<0.05$ was considered statistically significant.

\section{RESULTS}

Mean ages of premenopausal and postmenopausal women were $44.4 \pm 3.27$ (range: $40-49$ ) and $48.8 \pm 3.5$ (range: 40-59), respectively. AOPP levels of pre- and postmenopausal women were found to be $61.59 \pm 16.42 \mu \mathrm{mol} / \mathrm{L}$ and $123.83 \pm 55.51 \mu \mathrm{mol} / \mathrm{L}$ and MDA levels of pre- and postmenopausal women were found to be $5.98 \pm 0.77 \mu \mathrm{mol} / \mathrm{L}$ and $6.50 \pm 1.05 \mu \mathrm{mol} / \mathrm{L}$, respectively. Plasma AOPP and MDA levels in the postmenopausal women were increased when compared to their premenopausal peers $(p<0.05)$.

As the age range of the premenopausal group was 40 -49 years, the postmenopausal group was further subdivided into two groups as postmenopausal age of 40-49 years and postmenopausal age of 50-59 years to analyze the effect of age on AOPP and MDA levels. The results of the comparisons of mean plasma AOPP and MDA levels in the three groups are summarized in Table 1. Mean plasma AOPP levels of the two menopausal age groups were both significantly higher than the premenopausal group $(p<0.001)$. When plasma AOPP levels were compared between the two postmenopausal groups, although mean plasma AOPP levels of the older postmenopausal group were slightly higher 


\begin{tabular}{|l|c|c|c|c|} 
& \multicolumn{1}{|c|}{$\begin{array}{c}\text { Premenopausal } \\
\text { Age 40-49 } \\
\text { (n: 40) } \\
\text { (mean } \pm \text { SD) }\end{array}$} & $\begin{array}{c}\text { Postmenopausal } \\
\text { Age 40-49 } \\
\text { (n: 51) } \\
\text { (mean } \pm \text { SD) }\end{array}$ & $\begin{array}{c}\text { Postmenopausal } \\
\text { Age 50-59 } \\
\text { (n: 33) }\end{array}$ \\
\hline Age (years) & $44.4 \pm 3.3$ & $46.7 \pm 2.1$ & $52.3 \pm 2.2$ \\
\hline Duration of menopause (months) & - & $18.55 \pm 7.42$ & $21.58 \pm 8.30$ \\
\hline AOPP $[\mu \mathrm{mol} / \mathrm{L}]$ & $61.59 \pm 16.42^{*}$ & $118.64 \pm 59.12^{*}$ & $132.31 \pm 48.97^{*}$ \\
\hline MDA $[\mu \mathrm{mol} / \mathrm{L}]$ & $5.98 \pm 0.77^{* *}$ & $6.50 \pm 1.04^{* *}$ & $6.50 \pm 1.10^{* *}$ \\
\hline
\end{tabular}

*One-way ANOVA test, premenopausal vs. postmenopausal 40-49 age groups, and premenopausal vs. postmenopausal 50-59 age groups (post-hoc Scheffe test, $p=0.001$ ); **Kruskal-Wallis test, premenopausal vs. postmenopausal $40-49$ age groups (Kolmogorov-Smirnov test, $p=0.01$ ), and premenopausal vs. postmenopausal 50-59 age groups (Kolmogorov-Smirnov test, $p=0.02$ ). NS — not significant; AOPP — advanced oxidation protein products; MDA — malondialdehyde

\begin{tabular}{|c|c|c|c|}
\hline & $\begin{array}{l}\text { MDA } \\
\mathbf{p} \\
\mathbf{p}\end{array}$ & $\begin{array}{l}\text { Age } \\
r \\
p\end{array}$ & $\begin{array}{c}\text { Duration } \\
\text { of menopause } \\
\mathbf{r} \\
\mathbf{p}\end{array}$ \\
\hline AOPP & $\begin{array}{l}0.94 \\
0.32\end{array}$ & $\begin{array}{l}0.21 \\
0.78\end{array}$ & $\begin{array}{l}0.23 \\
0.56\end{array}$ \\
\hline MDA & & $\begin{array}{l}0.07 \\
0.95\end{array}$ & $\begin{array}{l}0.03 \\
0.98\end{array}$ \\
\hline
\end{tabular}

AOPP — advanced oxidation protein products; MDA — malondialdehyde

than the younger group, the difference was not statistically significant. Mean plasma MDA levels of the two postmenopausal age groups were both significantly higher from the premenopausal group $(p<0.01)$. Mean plasma MDA levels were not statistically different between the two postmenopausal age groups.

When the association between plasma AOPP and MDA levels and age or duration of menopause was analyzed with bivariate correlation procedure, no association between MDA and AOPP levels and age or duration of menopause was found. Also, there was no correlation between AOPP and MDA levels (Table 2).

\section{DISCUSSION}

Gender-specific differences in the incidence and severity of vascular diseases have been well-documented, with the lower incidence of cardiovascular diseases related to atherosclerosis in premenopausal women as compared to their postmenopausal peers or men of similar age [23]. The mechanisms responsible for these differences are likely to be multifactorial and ovarian sex-hormone dependent. The beneficial effect of ovarian sex-steroid production on the prevention of cardiovascular diseases has been confirmed by numerous reports linking oophorectomy, either before or after the menopause, to higher rates of cardiovascular diseases [24, 25]. Estrogen is the key hormone protecting women from vascular diseases via physiological effects on the important endothelial events [26]. Estrogens also have favorable effects on vascular oxidative stress by either increasing bioavailability of the vasoprotective molecule endothelium-derived nitric oxide or by modulating the expression and function of enzymes producing ROS, as well as antioxidant enzymes [27]. An increase in vascular oxidative stress in women after menopause has been reported in several studies [18-20, 28]. Furthermore, hormone replacement therapy has been shown to improve oxidative stress status of postmenopausal women [18, 29-32].

Our study demonstrated the obvious differences of oxidative stress markers between pre- and postmenopausal women. Although an increase in plasma levels of MDA, a marker of lipid peroxidation, in the postmenopausal period has been previously demonstrated [18-20], to the best of our knowledge this has been the first study to demonstrate menopause-related increase in plasma AOPP levels - a novel marker of oxidative protein damage reported to be associated with increased cardiovascular risk. In our study, mean plasma AOPP levels were significantly higher in postmenopausal as compared to premenopausal women, suggesting that it can be used as a marker in studies investigating cardiovascular risk in postmenopausal period. In contrast to our findings, a recent study investigating the relationship between oxidative stress and menopausal status found no differences in AOPP and MDA levels between pre- and postmenopausal women [21].

The value of AOPP assay as a marker for cardiovascular risk was reported in three other studies [15-17]. In two of these, the study populations were formed of non-uremic patients $[15,17]$. Kaneda et al., reported higher AOPP levels in the plasma of the patients with coronary artery disease diagnosed by angiography as compared to subjects without coronary artery disease [15]. They also found AOPP levels to be correlated with the severity of coronary artery disease. Skvarilova et al., also reported an association between higher plasma AOPP levels and angiographically confirmed coronary artery disease, and detected (ROC analysis) a cut-off level of $89 \mathrm{mmol} / \mathrm{L}$ to predict acute coronary syndrome with 
$64 \%$ sensitivity and $71 \%$ specificity [17]. Although study populations in these studies were older and their mean age was comparable to our study (around 60 years of age), it is not possible to compare AOPP levels from our study with other reports in the literature since only $25-36 \%$ of the cases were women. Further studies comparing AOPP levels between men and postmenopausal women of the same age groups, with or without coronary artery diseases, are needed to clarify the effect of age and gender on AOPP levels, as well as to detect critical cut-off levels to predict coronary artery disease in postmenopausal women [33].

Reports in the literature suggest that protein oxidation occurs in the plasma of coronary artery disease as well as uremic patients. AOPP levels were found to be significantly higher in the plasma of patients with coronary artery diseases than those without coronary artery disease. Also, a significant correlation had been detected by ANOVA between AOPP quartiles and the score and severity of coronary artery disease using the Gensini scoring system [15]. AOPPs are significantly increased in patients with acute coronary syndromes with ST segment elevation, but also tend to increase in patients with non-ST elevation myocardial infarction [17]. AOPPs may be used as markers of oxidative stress and as a prognostic factor for severe forms of cardiovascular diseases.

In our study, MDA levels were also found to be higher in postmenopausal women as compared to their premenopausal peers. Our results are consistent with the findings of a previous study comparing MDA levels between fertile and postmenopausal age groups [19]. Furthermore, two recent reports, investigating the effect of surgical menopause on oxidant and antioxidant status of perimenopausal patients, revealed that MDA levels were increased after surgical menopause $[18,20]$. Theoretically, MDA levels might further increase as the menopause continues to progress. We could not find any association between MDA levels and duration of menopause. This is in contrast with a previous report demonstrating a positive correlation between plasma MDA levels and duration of menopause [34]. However, the relatively shorter, as compared to the previous report, mean duration of menopause in our study might obscure any such association. Also, we were not able to find any association between AOPP levels and duration of menopause.

Oxidative stress probably accompanies the process of aging. A variety of oxidative stress markers have been demonstrated to change due to the aging process [9]. Although oxidative vascular stress of young women has been known to be lower as compared to men [23], the combined effect of aging and menopause in older women as compared to men is less certain. Thus, comparison of oxidative stress markers between the two genders in the elderly is needed to evaluate the independent effect of menopause on oxi- dative stress. MDA is one of the most often used biomarkers of oxidative stress on lipids associated with aging. An age-related increase in the plasma concentration of MDA has been documented in several studies $[28,33,35,36]$. Miguel $J$ et al., in their study on a group of healthy men and women ranging in age from 20 to 70 years, demonstrated an age-related increase in MDA levels only among the women [28]. In our study, no correlation between age and MDA levels was observed, possibly due to a narrow age range. In the elderly (aged between 61 and 70 years), mean serum MDA levels of women were interestingly higher than men in this study. Contrarily, although Özbay et al., demonstrated an age-related increase in MDA levels in healthy subjects aged between 9 to 71 years, they failed to demonstrate any gender differences in MDA levels in any age groups of 9-14, 27-45, and 57-71 years [33].

Free oxygen radicals are mainly formed as the result of oxygen reduction which takes place in the mitochondria. Unless these radicals are not antagonized by anti-oxidative system, cellular damage occurs [37]. In recent years, researchers have focused their attention on the role of these free radicals in the pathogenesis of many diseases, chief among them atherosclerosis, cancer, and diabetes. Ischemia, metabolic disorders, neutrophil activation, and cardiovascular diseases induce the production of free radicals and, consequently, cell damage with endothelial dysfunction [38].

AOPPs are considered reliable markers to estimate the degree of oxidant-mediated protein damage. Also, they have been proposed as one of the possible markers of oxidative injury, which originates under oxidative and carbonyl stress and increases global inflammatory activity [17]. Recently, the importance of advanced AOPP in the pathogenesis of atherosclerosis has been pointed out. These products originate as the result of free radical action on proteins and may act as inflammatory mediators triggering the oxidative 'ignition' of neutrophils, monocytes and T-lymphocytes, thus leading to up regulation and excessive stimulation of dendritic cells. These processes may account for immune disorders in atherosclerosis [39]. On the other hand, the antagonistic effect of AOPPs on high-density lipoprotein receptor by blocking HDL receptor scavenger receptor class B type I (SR-BI) gives rise to inhibition of $\mathrm{HDL}$, association to SR-BI and SR-BI-mediated cholesteryl ester uptake [40].

\section{CONCLUSIONS}

AOPP — as well as MDA — levels are elevated in postmenopausal women as compared to their premenopausal peers, suggesting that they can be used as markers for cardiovascular risk in the postmenopausal period. As far as future research and preventative prospects are concerned, several important aspects need to be considered regarding 
protein oxidation. Further studies will support the feasibility of assessing AOPP levels as predictive markers of cardiovascular risk in postmenopausal women.

\section{REFERENCES}

1. Sies H. Oxidative stress: from basic research to clinical application. $A m$ J Med. 1991, 91 (3C), 31S-38S.

2. Young IS, Woodside JV. Antioxidants in health and disease. J Clin Pathol. 2001, 54 (3), 176-186.

3. Valko $M$, Izakovic $M$, Mazur $M$, [et al.]. Role of oxygen radicals in DNA damage and cancer incidence. Mol Cell Biochem. 2004, 266 (1-2), 37-56.

4. Poli G, Leonarduzzi G, Biasi F, [et al.]. Oxidative stress and cell signalling. Curr Med Chem. 2004, 11 (9), 1163-1182.

5. Madamanchi NR, Vendrov A, Runge MS. Oxidative stress and vascular disease. Arterioscler Thromb Vasc Biol. 2005, 25 (1), 29-38.

6. Kalousova M, Zima T, Tesar V, [et al.]. Advanced glycoxidation end products in chronic diseases-clinical chemistry and genetic background. Mutation Res. 2005, 579 (1-2), 37-46.

7. Fridlyand LE, Philipson LH. Reactive species and early manifestation of insulin resistance in type 2 diabetes. Diabet Obes Metabol. 2006, 8 (2), 136-145.

8. Singh U, Jialal I. Oxidative stress and atherosclerosis. Pathophysiology 2006, 13 (3), 129-142.

9. Voss $\mathrm{P}$, Siems W. Clinical oxidation parameters of aging. Free Radical Res. 2006, 40 (12), 1339-1349.

10. de Zwart LL, Meerman JH, Commandeur JN, [et al.]. Biomarkers of free radical damage applications in experimental animals and in humans. Free Radical Biol Med. 1999, 26 (1-2), 202-226.

11. Dalle-Donne I, Rossi R, Colombo R, [et al.]. Biomarkers of oxidative damage in human disease. Clin Chem. 2006, 52 (4), 601-623.

12. Witko-Sarsat V, Friedlander M, Capeillere-Blandin C, [et al.]. Advanced oxidation protein products as a novel marker of oxidative stress in uremia. Kidney Int. 1996, 49 (5), 1304-1313.

13. Witko-Sarsat V, Friedlander M, Nguyen Khoa T, [et al.]. Advanced oxidation protein products as novel mediators of inflammation and monocyte activation in chronic renal failure. J Immunol. 1998, 161 (5), 2524-2532.

14. Capeillere-Blandin C, Gausson V, Descamps-Latscha B, [et al.]. Biochemical and spectrophotometric significance of advanced oxidized protein products. Biochim Biophys Acta. 2004, 1689 (2), 91-102.

15. Kaneda H, Taguchi J, Ogasawara K, [et al.]. Increased level of advanced oxidation protein products in patients with coronary artery disease. Atherosclerosis. 2002, 162 (1), 221-225.

16. Descamps-Latscha B, Witko-Sarsat V, Nguyen-Khoa T, [et al.]. Advanced oxidation protein products as risk factors for atherosclerotic cardiovascular events in nondiabetic predialysis patients. Am J Kidney Dis. 2005, 45 (1), 39-47.

17. Skvarilova M, Bulava A, Stejskal D, [et al.]. Increased level of advanced oxidation products (AOPP) as a marker of oxidative stress in patients with acute coronary syndrome. Biomed Pap Med Fac Univ Palacky Olomouc Czech Repub. 2005, 149 (1), 83-87.

18. Kumru S, Aydin S, Aras A, [et al.]. Effects of surgical menopause and estrogen replacement therapy on serum paraoxonase activity and plasma malondialdehyde concentration. Gynecol Obstetric Invest. 2005, 59 (2), 108-112.

19. Signorelli SS, Neri S, Sciacchitano S, [et al.]. Behaviour of some indicators of oxidative stress in postmenopausal and fertile women. Maturitas. 2006, 53 (1), 77-82

20. Kaur G, Mishra S, Kaur A, [et al.]. Retention of ovaries and oxidative stress of surgery. Int J Gynaecol Obstet. 2007, 97 (1), 40-43.
21. Victorino VJ, Panis C, Campos FC, [et al.]. Decreased oxidant profile and increased antioxidant capacity in naturally postmenopausal women. Age. 2013, 35 (4), 1411-1421.

22. Broekmans FJ, Kwee J, Hendriks DJ, [et al.]. A systematic review of tests predicting ovarian reserve and IVF outcome. Hum Reprod Update. 2006, $12(6), 685-718$.

23. Jousilahti $\mathrm{P}$, Vartiainen E, Tuomilehto J, [et al.]. Sex, age, cardiovascular risk factors, and coronary heart disease: a prospective follow-up study of 14786 middle-aged men and women in Finland. Circulation. 1999, 99 (9), 1165-1172.

24. Falkeborn $M$, Schairer $C$, Naessen T, [et al.]. Risk of myocardial infarction after oophorectomy and hysterectomy. J Clin Epidemiol. 2000, 53 (8), 832-827.

25. Parker WH, Broder MS, Liu Z, [et al.]. Ovarian conservation at the time of hysterectomy for benign disease. Clin Obstet Gynecol. 2007, 50 (2), 354-361.

26. Arnal JF, Scarabin PY, Tremollieres F, [et al.]. Estrogens in vascular biology and disease: where do we stand today? Curr Opin Lipid. 2007, 18 (5), 554-560.

27. Miller AA, De Silva TM, Jackman KA, [et al.]. Effect of gender and sex hormones on vascular oxidative stress. Clin Exp Pharmacol Physiol. 2007, 34 (10), 1037-1043.

28. Miquel J, Ramirez-Bosca A, Soler A, [et al.]. Increase with age of serum lipid peroxides: implications for the prevention of atherosclerosis. Mechanisms Ageing Develop. 1998, 100 (1), 17-24.

29. Leal M, Diaz J, Serrano E, [et al.]. Hormone replacement therapy for oxidative stress in postmenopausal women with hot flushes. Obstet Gynecol. 2000, 95 (6 Pt 1), 804-809.

30. Bednarek-Tupikowska G, Tworowska U, Jedrychowska I, [et al.]. Effects of oestradiol and oestroprogestin on erythrocyte antioxidative enzyme system activity in postmenopausal women. Clin Endocrinol (Oxf). 2006, 64 (4), 463-468.

31. Gokkusu C, Tata G, Ademoglu E, [et al.]. The benefits of hormone replacement therapy on plasma and platelet antioxidant status and fatty acid composition in healthy postmenopausal women. Platelets. 2010, 21 (6), 439-444.

32. Escalante Gomez C, Quesada Mora S. HRT decreases DNA and lipid oxidation in postmenopausal women. Climacteric. 2013, 16 (1), 104-110.

33. Ozbay B, Dulger H. Lipid peroxidation and antioxidant enzymes in Turkish population: relation to age, gender, exercise, and smoking. Tohoku J Exp Med. 2002, 197 (2), 119-124.

34. Signorelli SS, Neri S, Sciacchitano S, [et al.]. Duration of menopause and behavior of malondialdehyde, lipids, lipoproteins and carotid wall artery intima-media thickness. Maturitas. 2001, 39 (1), 39-42.

35. Mutlu-Turkoglu U, Ilhan E, Oztezcan S, [et al.]. Age-related increases in plasma malondialdehyde and protein carbonyl levels and lymphocyte DNA damage in elderly subjects. Clin Biochem. 2003, 36 (5), 397-400.

36. Gil L, Siems W, Mazurek B, [et al.]. Age-associated analysis of oxidative stress parameters in human plasma and erythrocytes. Free Radical Res. 2006, 40 (5), 495-505.

37. Halliwell B, Gutteridge JMC. Free radicals in biology and medicine. 4th ed. Oxford: Oxford University Press. 2007, xxxvi, 851 p.

38. Indik JH, Goldman $\mathrm{S}$, Gaballa MA. Oxidative stress contributes to vascular endothelial dysfunction in heart failure. Am J Physiol. Heart Circ Physiol. 2001, 281 (4), H1767-H1770.

39. Woods AA, Linton SM, Davies MJ. Detection of $\mathrm{HOCl}$-mediated protein oxidation products in the extracellular matrix of human atherosclerotic plaques. Biochem J. 2003, 370 (Pt 2), 729-735.

40. Marsche G, Frank S, Hrzenjak A, [et al.]. Plasma-advanced oxidation protein products are potent high-density lipoprotein receptor antagonists in vivo. Circ Res. 2009, 104 (6), 750-757. 